\title{
Efficacy of the $\mathrm{FEV}_{1} / \mathrm{FEV}_{6}$ ratio compared to the $F E V_{1} / F V C$ ratio for the diagnosis of airway obstruction in subjects aged 40 years or over
}

\footnotetext{
F.W. Rosa ${ }^{1,2,3}$,

R. Perez-Padilla ${ }^{4}$,

A. Camelier ${ }^{1,3,5}$,

O.A. Nascimento ${ }^{1}$

A.M.B. Menezes ${ }^{6}$,

J.R. Jardim ${ }^{1}$ and

Latin American Project for the Investigation of

Obstructive Lung Disease (PLATINO) Group ${ }^{7}$
}

\author{
1Disciplina de Pneumologia e Centro de Reabilitação Pulmonar, \\ Escola Paulista de Medicina, Universidade Federal de São Paulo, São Paulo, SP, Brasil \\ ${ }^{2}$ Universidade Católica do Salvador, Salvador, BA, Brasil \\ ${ }^{3}$ Faculdade de Tecnologia e Ciências, Salvador, BA, Brasil \\ ${ }^{4}$ National Institute of Respiratory Diseases, Mexico, DF, Mexico \\ ${ }^{5}$ Disciplina de Pneumologia, Universidade Federal da Bahia, Salvador, BA, Brasil \\ ${ }^{6}$ Programa de Pós-graduação em Epidemiologia, Universidade Federal de Pelotas, \\ Pelotas, RS, Brasil \\ ${ }^{7}$ PLATINO Group: A.M.B. Menezes (Brasil), J.R. Jardim (Brasil), R. Pérez-Padilla \\ (Mexico), A. Muino (Uruguay), M.V. López (Uruguay), G. Valdivia (Chile), \\ M.M. de Oca (Venezuela), C. Tálamo (Venezuela)
}

\section{Correspondence \\ J.R. Jardim \\ Disciplina de Pneumologia \\ EPM, Unifesp \\ Rua Botucatu, 740, 3ํandar \\ 04023-062 São Paulo, SP \\ Brasil \\ Fax: +55-11-5573-5035 \\ E-mail: joserjardim@yahoo.com.br \\ fwrosa@yahoo.com.br}

Research partially supported by Boehringher-Ingelheim International, CAPES, FAPESP, and CNPq

Received October 29, 2006 Accepted July 10, 2007

\section{Abstract}

The present cross-sectional, population-based study was designed to evaluate the performance of the $\mathrm{FEV}_{1} / \mathrm{FEV}_{6}$ ratio for the detection of airway-obstructed subjects compared to the $\mathrm{FEV}_{1} / \mathrm{FVC}<0.70$ fixed ratio test, as well as the lower limit of normality (LLN) for 1000 subjects $\geq 40$ years of age in the metropolitan area of São Paulo, SP, Brazil. After the exclusion of 37 (3.7\%) spirometries, a total of 963 pre-bronchodilator (BD) and 918 post-BD curves were constructed. The majority of the post-BD curves $(93.1 \%)$ were of very good quality and achieved grade $\mathrm{A}$ ( 762 curves) or $\mathrm{B}$ (93 curves). The $\mathrm{FEV}_{1} / \mathrm{FEV}_{6}$ and $\mathrm{FEV}_{1} / \mathrm{FVC}$ ratios were highly correlated $\left(\mathrm{r}^{2}=0.92, \mathrm{P}<0.000\right)$. Two receiver operator characteristic curves were constructed in order to express the imbalance between the sensitivity and specificity of the $\mathrm{FEV}_{1} / \mathrm{FEV}_{6}$ ratio compared to two $\mathrm{FEV}_{1} / \mathrm{FVC}$ cut-off points for airway obstruction: equal to 70 (area under the curve $=0.98, \mathrm{P}<$ 0.0001 ) and the LLN (area under the curve $=0.97, \mathrm{P}<0.0001$ ), in the post-BD curves. According to an $\mathrm{FEV}_{1} / \mathrm{FVC}<0.70$, the cut-off point for the $\mathrm{FEV}_{1} / \mathrm{FEV}_{6}$ ratio with the highest sum for sensitivity and specificity was 0.75 . The $\mathrm{FEV}_{1} / \mathrm{FEV}_{6}$ ratio can be considered to be a good alternative to the $\mathrm{FEV}_{1} / \mathrm{FVC}$ ratio for the diagnosis of airway obstruction, both using a fixed cut-off point or below the LLN as reference. The $\mathrm{FEV}_{1} / \mathrm{FEV}_{6}$ ratio has the additional advantage of being an easier maneuver for the subjects and for the lung function technicians, providing a higher reproducibility than traditional spirometry maneuvers.
Key words

- Forced expiratory volume in six seconds

- Airway obstruction

- Diagnosis

- Forced vital capacity

- Pulmonary function tests

- Spirometry 


\section{Introduction}

The definition of airflow limitation by spirometry classically considers either a $\mathrm{FEV}_{1} / \mathrm{FVC}$ ratio $<0.70$ or a value below the lower limit of normality (LLN) derived from reference equations (1-3). Some studies have recently suggested that reducing the forced expiratory maneuver to a 6-s duration (also called $\mathrm{FEV}_{6}$ ) could replace the forced vital capacity (FVC) maneuver as a surrogate of the $\mathrm{FEV}_{1} / \mathrm{FVC}$ ratio for the diagnosis of airway obstruction (4-8). The advantages of $\mathrm{FEV}_{6}$ described in the literature are: easy execution (for patients and technicians) $(9,10)$, elimination of very low flow sensor accuracy limitations at the end of FVC maneuvers, reduction in the total duration of the spirometry test, and possibly a reduction in spirometry complications (such as syncope) (11-13).

Analysis of published studies shows that the criteria adopted to define obstruction from the $\mathrm{FEV}_{1} / \mathrm{FEV}_{6}$ ratio are quite variable: some studies used the sensitivity and specificity values associated with receiver operator characteristic (ROC) curve analysis to find the best cut-off point $(3,6)$, some used an empiric fixed $\mathrm{FEV}_{1} / \mathrm{FEV}_{6}$ ratio of 0.70 (4), and finally others used the LLN, derived from reference equations, as the best option $(5,7,11,12,14)$. Important limitations of such studies are: the reference equations used were developed in a setting different from that of the subjects in whom the $\mathrm{FEV}_{1} / \mathrm{FEV}_{6}$ ratio was measured and there was a wide variation in the population concerning age, height, weight, and ethnicity, possibly leading to a limitation of the external validation (8). Finally, there was the possibility of a selection bias since some studies were conducted on patients referred to pulmonary function test laboratories, a fact that might influence the accuracy of the $\mathrm{FEV}_{1} / \mathrm{FEV}_{6}$ ratio $(4,5,9,11,14)$.

The PLATINO study was conducted in order to determine the prevalence of chronic obstructive pulmonary disease (COPD) in the population of five large cities in Latin America (15). Spirometric reference equations derived from the PLATINO study (including $\mathrm{FEV}_{6}$ and $\mathrm{FEV}_{1} / \mathrm{FEV}_{6}$ ) have been published (3). Specific data regarding the Brazilian subsample are available (16).

The present study was designed to evaluate the performance of the $\mathrm{FEV}_{1} / \mathrm{FEV}_{6}$ ratio in detecting airflow limitation using the $\mathrm{FEV}_{1} / \mathrm{FVC}<0.70$ fixed ratio and LLN in the Brazilian subsample of the PLATINO study.

\section{Material and Methods}

\section{Participants}

Between December 2002 and March 2003, subjects aged 40 years and over (COPD target population) were recruited according to a multi-stage cluster sampling strategy, in order to obtain representative samples of adults living in the metropolitan area of São Paulo, the largest city in South America (690 $\mathrm{m}$ above sea level and $23^{\circ}$ latitude South), which has a population of 17.3 million people. Within the 1113 households sampled there were 1150 individuals eligible for the study; of these, 1000 answered the questionnaires, and 963 performed spirometry (with 918 completing the post-bronchodilator (BD) phase). The overall non-response rate was $15.3 \%$, taking into account both household and individual contact failures and refusals (including refusals only for spirometry). Therefore, spirometry analyses were carried out using the post-BD curves.

\section{Instruments and examinations}

The PLATINO core questionnaire is a composite including sections of the following questionnaires: ATS/DLD (17), European Community Respiratory Health Survey II (18) and Lung Health Study (19). It contains questions about respiratory symptoms, COPD risk factors, previous medi- 
cal diagnosis and diagnostic tests, and medications. The exclusion criteria for the study were mental disease and institutionalization.

\section{Anthropometric measurements}

Height and weight were measured with a portable Seca ${ }^{\circledR}$ stadiometer (Hamburg, Germany) with $0.1-\mathrm{cm}$ precision and an electronic Tanita ${ }^{\circledR}$ scale (Tokyo, Japan) with 200-g precision, respectively. Body mass index was calculated by dividing weight by squared height $\left(\mathrm{kg} / \mathrm{m}^{2}\right)$.

\section{Spirometry}

Spirometry was carried out by personnel who had received training in a quality control course for spirometry testing approved by the National Institute for Occupational Safety and Health. Two spirometric readings were taken, one at baseline, and the other $15 \mathrm{~min}$ after the application of $200 \mu \mathrm{g}$ salbutamol through a spacer, and their reproducibility was graded according to quality control grades A to F. Subjects were seated and used nose clips. An ultrasound spirometer (Easy One, NDD Technopark, Zurich, Switzerland), which met all ATS quality control criteria was used (20). Calibration was verified daily with a $3-\mathrm{L}$ syringe. All spirometry results were sent to the investigators in the Quality Control center, located in Mexico City, Mexico, and a weekly feedback report to the center in São Paulo, Brazil, was provided (21). The spirometry reference equations used in the present study were developed from the data for five Latin American cities in the PLATINO study, including São Paulo (3). $\mathrm{FEV}_{6}$ was obtained from the same FVC curve. Exclusion criteria for spirometry were: thoracic or abdominal surgery, myocardial infarction, eye surgery (or detached retina), and hospitalization for any cardiac problem in the previous three months, as well as current treatment for tuberculosis or pregnancy.

\section{Statistical analysis}

Data are reported as means $\pm \mathrm{SD}$. The Student $t$-test and ANOVA were used to compare means. The performance of the separate sets of variables was analyzed using two-by-two tables. Sensitivity, specificity, positive predictive value, negative predictive value, and ROC curves were calculated and compared using a fixed cut-off point of $\mathrm{FEV}_{1} / \mathrm{FVC}<0.70$ or based on the identification of the LLN (derived from the PLATINO spirometry reference equations) as reference for airway obstruction (3). The level of significance was set at $\mathrm{P}<0.05$. Analyses were carried out using the STATA and SPSS (v13) programs.

\section{Ethics}

The Ethics Committee of the Federal University of São Paulo approved the study and written informed consent was obtained from each subject. For additional data, we suggest consultation of PLATINO methods (22).

\section{Results}

\section{Sample baseline characteristics}

One thousand subjects aged 40 years or more were interviewed in the great metropolitan area of São Paulo, Brazil. Thirtyseven $(3.7 \%)$ subjects did not meet the inclusion criteria for spirometry, 963 subjects performed pre-BD spirometry and $918 \mathrm{com}-$ pleted the post-BD phase. The baseline characteristics of the sample studied are shown in Table 1.

Twenty-four percent of the subjects (240) were current smokers and $9.1 \%$ (91 patients) were former smokers.

\section{Spirometry quality control}

Quality control of the flow-volume curves 
Table 1. Characteristics of the study group.

\begin{tabular}{|c|c|}
\hline Variables & Mean \pm SD \\
\hline Age (years) & $55.2 \pm 11.3$ \\
\hline Weight $(\mathrm{kg})$ & $70 \pm 15.7$ \\
\hline Height $(\mathrm{cm})$ & $160.1 \pm 9.5$ \\
\hline BMI $\left(\mathrm{kg} / \mathrm{m}^{2}\right)$ & $27.3 \pm 5.6$ \\
\hline Tobacco exposure (pack-years) & $18.3 \pm 22.7$ \\
\hline FVC $(\mathrm{L})$ pre-BD & $3.4 \pm 1$ \\
\hline $\mathrm{FEV}_{1}(\mathrm{~L})$ pre-BD & $2.6 \pm 0.8$ \\
\hline $\mathrm{FEV}_{1} / \mathrm{FVC}(\%)$ pre-BD & $75.6 \pm 9.4$ \\
\hline $\mathrm{FEV}_{6}(\mathrm{~L})$ pre-BD & $3.3 \pm 1$ \\
\hline $\mathrm{FEV}_{1} / \mathrm{FEV}_{6}(\%)$ pre-BD & $78.7 \pm 7.6$ \\
\hline FVC (L) post-BD & $3.4 \pm 0.95$ \\
\hline $\mathrm{FEV}_{1}(\mathrm{~L})$ post-BD & $2.7 \pm 0.8$ \\
\hline $\mathrm{FEV}_{1} / \mathrm{FVC}(\%)$ post-BD & $77 \pm 9.2$ \\
\hline $\mathrm{FEV}_{6}(\mathrm{~L})$ post-BD & $3.3 \pm 0.9$ \\
\hline $\mathrm{FEV}_{1} / \mathrm{FEV}_{6}(\%)$ post-BD & $80.7 \pm 7.3$ \\
\hline Intratest coefficient of variability of post-BD FEV 6 & $2.23 \pm 7.3$ \\
\hline Intratest coefficient of variability of post-BD FVC & $1.86 \pm 2.25$ \\
\hline Intratest coefficient of variability of post-BD $\mathrm{FEV}_{1} / \mathrm{FEV}_{6}$ & $0.74 \pm 0.92$ \\
\hline Intratest coefficient of variability of post-BD $\mathrm{FEV}_{1} / \mathrm{FVC}$ & $1.23 \pm 1.51$ \\
\hline
\end{tabular}

Table 2. Sensitivity and specificity of the $\mathrm{FEV}_{1} / \mathrm{FEV}_{6}$ ratio compared to $\mathrm{FEV}_{1} / \mathrm{FVC}=70$, pre-BD curves.

\begin{tabular}{llccrr}
\hline & \multicolumn{3}{c}{ Pre-BD FEV $1 / F V C=70$} \\
\cline { 2 - 5 } & \multicolumn{1}{c}{ Sensitivity } & Specificity & PPV & NPV & Prevalence \\
\hline $\mathrm{FEV}_{1} / \mathrm{FEV}_{6}=70$ & $47.9 \%(41.2-54.8)$ & $100 \%(99.4-100)$ & $100 \%(95.6-100)$ & $86.7 \%(84.3-88.9)$ & $10.9 \%(9.0-13.1)$ \\
$\mathrm{FEV}_{1} / \mathrm{FEV}_{6}=71$ & $56.6 \%(49.8-63.2)$ & $99.7 \%(98.9-100)$ & $98.4 \%(93.8-99.7)$ & $88.6 \%(86.2-90.7)$ & $13.1 \%(11.0-15.3)$ \\
$\mathrm{FEV}_{1} / \mathrm{FEV}_{6}=72$ & $63.9 \%(57.1-70.2)$ & $99.4 \%(98.5-99.8)$ & $97.2 \%(92.6-99.1)$ & $90.4 \%(88.1-92.2)$ & $15.0 \%(12.8-17.4)$ \\
$\mathrm{FEV}_{1} / \mathrm{FEV}_{6}=73$ & $73.0 \%(66.6-78.7)$ & $99.1 \%(97.9-99.5)$ & $95.8 \%(91.2-98.1)$ & $92.9 \%(90.8-94.5)$ & $17.3 \%(15.0-19.9)$ \\
$\mathrm{FEV}_{1} / \mathrm{FEV}_{6}=74$ & $83.1 \%(77.3-87.7)$ & $98.1 \%(96.8-98.9)$ & $92.9 \%(88.1-95.9)$ & $95.2 \%(93.3-96.5)$ & $20.4 \%(17.9-23.1)$ \\
$\mathrm{FEV}_{1} / \mathrm{FEV}_{6}=75$ & $89.0 \%(84.0-92.7)$ & $95.4 \%(93.6-96.8)$ & $85.2 \%(79.7-89.4)$ & $96.7 \%(95.1-97.8)$ & $23.8 \%(21.2-26.6)$ \\
$\mathrm{FEV}_{1} / \mathrm{FEV}_{6}=76$ & $94.06 \%(89.8-96.7)$ & $91.0 \%(88.6-92.9)$ & $75.5 \%(69.8-80.3)$ & $98.1 \%(96.7-98.9)$ & $28.3 \%(25.5-31.3)$ \\
$\mathrm{FEV}_{1} / \mathrm{FEV} 6=77$ & $95.89 \%(92.1-98.0)$ & $85.7 \%(83.0-88.1)$ & $66.5 \%(60.9-71.6)$ & $98.6 \%(97.3-99.3)$ & $32.8 \%(29.9-35.9)$ \\
$\mathrm{FEV}_{1} / \mathrm{FEV}_{6}=78$ & $97.7 \%(94.4-99.2)$ & $80.0 \%(76.9-82.8)$ & $59.0 \%(53.7-64.0)$ & $98.8 \%(97.5-99.5)$ & $37.7 \%(34.6-40.8)$ \\
$\mathrm{FEV}_{1} / \mathrm{FEV}_{6}=79$ & $98.6 \%(95.7-99.6)$ & $72.3 \%(69.3-75.9)$ & $51.7 \%(46.8-56.5)$ & $99.4 \%(98.2-99.8)$ & $43.5 \%(40.4-46.7)$
\end{tabular}

Data are reported as percent with $95 \%$ confidence intervals in parentheses. PPV = positive predictive value; NPV = negative predictive value. For other abbreviations, see legend to Table 1.

Table 3. Sensitivity and specificity of the $\mathrm{FEV}_{1} / \mathrm{FEV}_{6}$ ratio compared to $F E V_{1} / F V C=0.70$, post-BD curves.

\begin{tabular}{llcccc}
\hline & \multicolumn{3}{c}{ Post-BD FEV $1 / F V C=70$} \\
\cline { 2 - 6 } & \multicolumn{1}{c}{ Sensitivity } & Specificity & PPV & NPV & Prevalence \\
\hline $\mathrm{FEV}_{1} / \mathrm{FEV}_{6}=70$ & $44.4 \%(36.2-52.9)$ & $100 \%(99.4-100)$ & $100 \%(92.9-100)$ & $90.6 \%(88.4-92.5)$ & $7.0 \%(5.4-8.9)$ \\
$\mathrm{FEV}_{1} / \mathrm{FEV}_{6}=71$ & $54.9 \%(46.4-63.1)$ & $100 \%(99.4-100)$ & $100 \%(94.2-100)$ & $92.3 \%(90.1-94.0)$ & $8.6 \%(6.9-10.6)$ \\
$\mathrm{FEV}_{1} / \mathrm{FEV}_{6}=72$ & $60.4 \%(51.9-68.4)$ & $99.6 \%(98.8-99.9)$ & $96.7 \%(89.9-99.1)$ & $93.11 \%(91.1-94.7)$ & $9.8 \%(8.0-12.0)$ \\
$\mathrm{FEV}_{1} / \mathrm{FEV} 6=73$ & $72.2 \%(64.0-79.2)$ & $99.5 \%(98.6-99.8)$ & $96.3 \%(90.2-98.8)$ & $95.1 \%(93.3-96.4)$ & $11.8 \%(9.8-14.1)$ \\
$\mathrm{FEV}_{1} / \mathrm{FEV} 6=74$ & $79.2 \%(71.4-85.3)$ & $99.0 \%(97.9-99.5)$ & $93.44 \%(87.1-96.9)$ & $96.2 \%(94.6-97.4)$ & $13.3 \%(11.2-15.7)$ \\
$\mathrm{FEV}_{1} / \mathrm{FEV}_{6}=75$ & $88.2 \%(81.5-92.8)$ & $97.4 \%(96.0-98.4)$ & $86.4 \%(79.5-91.3)$ & $97.8 \%(96.4-98.7)$ & $16.0 \%(13.7-18.6)$ \\
$\mathrm{FEV}_{1} / \mathrm{FEV}_{6}=76$ & $90.3 \%(83.9-94.4)$ & $93.7 \%(91.2-94.9)$ & $73.44 \%(66.2-79.7)$ & $98.1 \%(96.8-98.9)$ & $19.3 \%(16.8-22.0)$ \\
$\mathrm{FEV}_{1} / \mathrm{FEV}_{6}=77$ & $93.1 \%(87.3-96.4)$ & $90.6 \%(88.2-92.5)$ & $64.7 \%(57.8-71.1)$ & $98.6 \%(97.3-99.3)$ & $22.54 \%(19.9-25.4)$ \\
$\mathrm{FEV}_{1} / \mathrm{FEV}_{6}=78$ & $94.4 \%(89.0-97.4)$ & $86.2 \%(83.3-88.5)$ & $56.0 \%(49.5-62.3)$ & $98.8 \%(97.6-99.4)$ & $26.4 \%(23.6-29.4)$ \\
$\mathrm{FEV}_{1} / \mathrm{FEV}_{6}=79$ & $97.2 \%(92.1-99.1)$ & $80.87 \%(86.2-90.8)$ & $48.6 \%(42.7-54.5)$ & $98.4 \%(98.3-99.8)$ & $31.4 \%(28.4-34.5)$ \\
\hline
\end{tabular}

Data are reported as percent with $95 \%$ confidence intervals in parentheses. PPV = positive predictive value; NPV = negative predictive value. For other abbreviations, see legend to Table 1. 
was evaluated by analyzing the reproducibility of the three best curves for each subject, in both phases of spirometry (pre- and post-BD). The majority of the post-BD curves $(93.1 \%)$ was of very good quality, achieving grade A (762 curves) or B (93 curves). Twenty-eight curves achieved grade $\mathrm{C}(3.05 \%)$ and 35 (3.8\%) achieved $\mathrm{D}, \mathrm{E}$, or $\mathrm{F}$ grades.

\section{Analysis of the sensitivity and specificity of the $\mathrm{FEV}_{1} / \mathrm{FEV}_{6}$ ratio}

Before the analysis of accuracy, a scatterplot graph between post-BD $\mathrm{FEV}_{1} / \mathrm{FEV}_{6}$ and $\mathrm{FEV}_{1} / \mathrm{FVC}$ ratios was constructed, and $\mathrm{r}^{2}=0.92(\mathrm{P}<0.000)$ was found.

A $\mathrm{FEV}_{1} / \mathrm{FVC}$ ratio of 0.70 was taken as the reference value for the diagnosis of airway obstruction. The sensitivity and specificity of the $\mathrm{FEV}_{1} / \mathrm{FEV}_{6}$ ratio were analyzed for both the pre-BD and post-BD curves (Tables 2 and 3, respectively). The highest sum of sensitivity and specificity was detected with an $\mathrm{FEV}_{1} / \mathrm{FEV}_{6}$ ratio threshold of 0.75 post-BD. Two ROC curves were constructed in order to express the balance between the sensitivity and specificity of the $\mathrm{FEV}_{1} / \mathrm{FEV}_{6}$ ratio compared to two $\mathrm{FEV}_{1} /$ FVC cut-off points for airway obstruction: one considered values equal to 0.70 and the other values below the LLN. The results are shown in Figure 1.

\section{COPD diagnosis and misclassification according to the post-BD $\mathrm{FEV}_{1} / \mathrm{FEV}_{6}$ ratio}

The diagnosis of air flow limitation according to a fixed post-BD $\mathrm{FEV}_{1} / \mathrm{FVC}$ ratio $<0.70$ (as stated by the ATS/ERS and Brazilian guidelines) was compared to the diagnosis of air flow based on a post-BD $\mathrm{FEV}_{1} / \mathrm{FEV}_{6}$ ratio $<0.75$, using a $2 \times 2$ table (Table 4). Based on an $\mathrm{FEV}_{1} / \mathrm{FVC}$ ratio $<0.70,15.7 \%$ of the sample was considered to have airway obstruction, while this number slightly increased to $16.03 \%$ taking into consideration an $\mathrm{FEV}_{1} / \mathrm{FEV}_{6}$ ratio $<75 \%$.
The positive and negative predictive values were 85.8 and $97.8 \%$, respectively. Discordant diagnosis was found in $4.14 \%$ of cases (Table 4).

A cut-off point using the LLN derived from PLATINO reference equations was also analyzed (Table 5). A discordant diagnosis

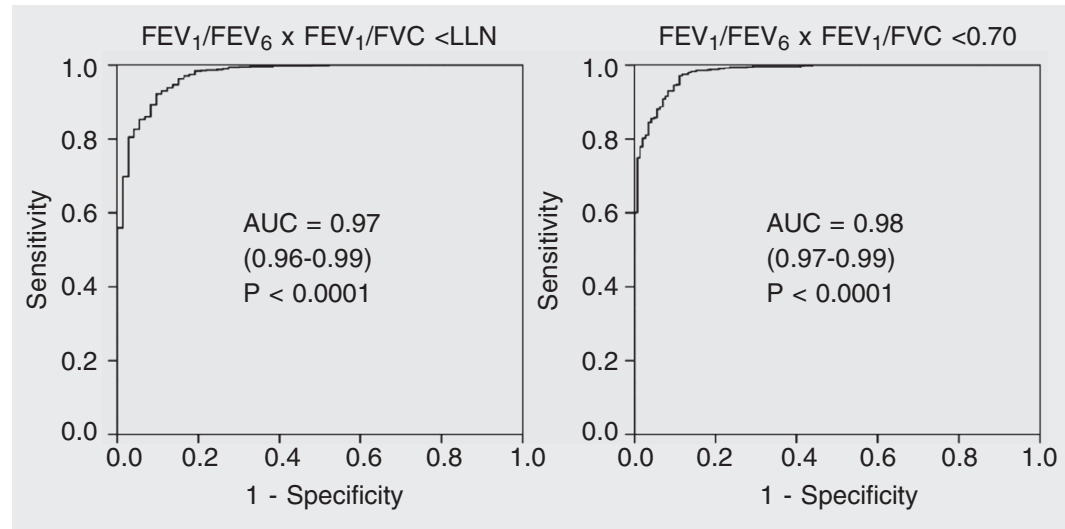

Figure 1. Area under the receiver operator characteristic curves (AUC) and $95 \%$ confidence intervals for the $F E V_{1} / F E V_{6}$ ratio compared to an $\mathrm{FEV}_{1} / \mathrm{FVC}$ ratio equal to the lower limit of normality (LLN) and to 0.70 . FEV = forced expiratory volume; $F V C=$ forced vital capacity.

Table 4. Analysis of discordant cases when using the $\mathrm{FEV}_{1} / \mathrm{FEV}_{6}<75$ and $\mathrm{FEV}_{1} / \mathrm{FVC}<70$ ratios for airway obstruction with post-BD curves.

\begin{tabular}{lrrr}
\hline FEV $_{1} / \mathrm{FEV}_{6}$ & \multicolumn{2}{c}{$\mathrm{FEV}_{1} / \mathrm{FVC}$} & Total \\
\cline { 2 - 3 } & $<70 \%$ & $\geq 70 \%$ & \\
\hline$<75 \%$ & 127 & 21 & 148 \\
& 17 & 753 & 770 \\
Total & 144 & 773 & 918 \\
\hline
\end{tabular}

For abbreviations, see legend to Table 1.

Table 5. Analysis of the discordant cases when using the $\mathrm{FEV}_{1} / \mathrm{FEV}_{6}$ and $\mathrm{FEV}_{1} / \mathrm{FVC}$ ratio $<\mathrm{LLN}$ for airway obstruction with post-BD curves.

\begin{tabular}{|c|c|c|c|}
\hline \multirow[t]{2}{*}{$\mathrm{FEV}_{1} / \mathrm{FEV}_{6}$} & \multicolumn{2}{|c|}{$\mathrm{FEV}_{1} / \mathrm{FVC}$ post-BD } & \multirow[t]{2}{*}{ Total } \\
\hline & $<$ LLN & $\geq \mathrm{LLN}$ & \\
\hline$<L L N$ & 117 & 17 & 134 \\
\hline$\geq \mathrm{LLN}$ & 23 & 806 & 829 \\
\hline Total & 140 & 823 & 963 \\
\hline
\end{tabular}

LLN = lower limit of normality. For other abbreviations, see legend to Table 1. 
was present in $40(4.35 \%)$ of the subjects studied.

\section{Discussion}

The present study showed that the $\mathrm{FEV}_{1} /$ $\mathrm{FEV}_{6}$ ratio is a good substitute for the detection of airway-obstructed subjects using either an $\mathrm{FEV}_{1} / \mathrm{FVC}$ ratio $<0.70$ (fixed ratio) or a threshold below the LLN as reference. The main strengths of the present study are the fact that the study group consisted of a randomized population-based sample $(15,16)$ and the use of a set of spirometry reference equations derived from the same sample (3). The best cut-off point of the $\mathrm{FEV}_{1} / \mathrm{FEV}_{6}$ ratio was 0.75 . These aspects were considered to be points to be addressed in future studies (9). Two other studies showed a similar cut-off point $(0.73)$ of the $\mathrm{FEV}_{1} / \mathrm{FEV}_{6}$ ratio for the detection of airway obstruction, both using the fixed $\mathrm{FEV}_{1} / \mathrm{FVC}<0.70$ ratio for comparison. Vandevoorde et al. (9) used a spirometry database of referenced patients from a medical facility, whereas Melbye et al. (10) recruited subjects from a highly homogeneous population-based sample in a northern city of Norway. Despite the different population background between these two studies and the present one, a similar cut-off point for the $\mathrm{FEV}_{1} / \mathrm{FEV}_{6}$ ratio was found. The advantage of using a fixed cutoff value for the $\mathrm{FEV}_{1} / \mathrm{FEV}_{6}$ ratio instead of choosing the LLN from a reference equation to diagnose airway obstruction is emphasized by the main COPD guidelines $(1,13)$. The specific use of the $\mathrm{FEV}_{1} / \mathrm{FEV}_{6}$ ratio for the diagnosis of airflow obstruction has the advantage of being less time consuming and easier for the patient and technician. This should be an interesting point to consider when establishing diagnostic units for respiratory diseases in large primary care centers.

Analysis of the ROC curves for the $\mathrm{FEV}_{1} /$ FVC ratio using the value below 0.70 and lower values than the LLN as cut-off points to predict the best accuracy showed similar results in identifying a cut-off for the $\mathrm{FEV}_{1} /$ $\mathrm{FEV}_{6}$ ratio according to the analysis of the 95\% CI (Tables 2, 3, 4, and 5, Figure 1). Besides the fact that the two parameters had an excellent correlation, the best cut-off point to be chosen in clinical practice should take into account the proportion of wrong diagnoses (discordant cases), which in the present study could be considered small, i.e., about 4\% (Tables 4 and 5).

The authors believe that this new information will set a new basis for the clinical judgment of which parameter and cut-off point should be chosen as a reference for clinical use.

\section{Study limitations}

The present study was originally designed to estimate COPD prevalence in a population-based survey. The reference values used in this study were based on those obtained for the residents of five Latin American cities of the PLATINO study (15) as a whole. Considered separately, no city subsample had enough power to develop local equations.

We may conclude that the $\mathrm{FEV}_{1} / \mathrm{FEV}_{6}$ ratio can be considered a good alternative to the $\mathrm{FEV}_{1} / \mathrm{FVC}$ ratio in the diagnosis of airway obstruction, either considering a fixed cut-off point or a value below the LLN.

\section{References}

1. Celli BR, MacNee W; ATS/ERS Task Force. Standards for the diagnosis and treatment of patients with COPD: a summary of the ATS/ERS position paper. Eur Respir J 2004; 23: 932-946.

2. Fabbri LM, Luppi F, Beghe B, Rabe KF. Update in chronic obstruc- tive pulmonary disease 2005. Am J Respir Crit Care Med 2006; 173: 1056-1065.

3. Perez-Padilla R, Valdivia G, Muino A, Lopez MV, Marquez MN, Montes de Oca M, et al. Spirometric reference values in 5 large Latin 
American cities for subjects aged 40 years or over. Arch Bronconeumol 2006; 42: 317-325.

4. Demir T, Ikitimur HD, Koc N, Yildirim N. The role of FEV 6 in the detection of airway obstruction. Respir Med 2005; 99: 103-106.

5. Vandevoorde J, Verbanck S, Schuermans D, Kartounian J, Vincken W. $\mathrm{FEV}_{1} / \mathrm{FEV}_{6}$ and $F E V_{6}$ as an alternative for $F E V_{1} / F V C$ and $F V C$ in the spirometric detection of airway obstruction and restriction. Chest 2005; 127: 1560-1564.

6. Vandevoorde J, Verbanck S, Schuermans D, Vincken W. The role of $\mathrm{FEV}_{6}$ in the detection of airway obstruction. Respir Med 2005; 99: 1465-1466.

7. Akpinar-Elci M, Fedan KB, Enright PL. FEV 6 as a surrogate for FVC in detecting airways obstruction and restriction in the workplace. Eur Respir J 2006; 27: 374-377.

8. Gleeson S, Mitchell B, Pasquarella C, Reardon E, Falsone J, Berman L. Comparison of FEV 6 and FVC for detection of airway obstruction in a community hospital pulmonary function laboratory. Respir Med 2006; 100: 1397-1401.

9. Vandevoorde J, Verbanck S, Schuermans D, Kartounian J, Vincken W. Obstructive and restrictive spirometric patterns: fixed cut-offs for $\mathrm{FEV}_{1} / \mathrm{FEV}_{6}$ and $\mathrm{FEV}_{6}$. Eur Respir J 2006; 27: 378-383.

10. Melbye $\mathrm{H}$, Medbo $A$, Crockett $A$. The $F E V_{1} / F_{E V}$ ratio is a good substitute for the $\mathrm{FEV}_{1} / \mathrm{FVC}$ ratio in the elderly. Prim Care Respir $J$ 2006; 15: 294-298.

11. Swanney MP, Beckert LE, Frampton CM, Wallace LA, Jensen RL, Crapo RO. Validity of the American Thoracic Society and other spirometric algorithms using FVC and forced expiratory volume at 6 s for predicting a reduced total lung capacity. Chest 2004; 126 : 1861-1866.

12. Hansen JE, Sun XG, Wasserman K. Should forced expiratory volume in six seconds replace forced vital capacity to detect airway obstruction? Eur Respir J 2006; 27: 1244-1250.

13. Ferguson GT, Enright PL, Buist AS, Higgins MW. Office spirometry for lung health assessment in adults: A consensus statement from the National Lung Health Education Program. Chest 2000; 117: 1146-1161.

14. Swanney MP, Jensen RL, Crichton DA, Beckert LE, Cardno LA, Crapo RO. FEV(6) is an acceptable surrogate for FVC in the spirometric diagnosis of airway obstruction and restriction. Am J Respir Crit Care Med 2000; 162: 917-919.

15. Menezes AM, Perez-Padilla R, Jardim JR, Muino A, Lopez MV, Valdivia G, et al. Chronic obstructive pulmonary disease in five Latin American cities (the PLATINO study): a prevalence study. Lancet 2005; 366: 1875-1881.

16. Menezes AM, Jardim JR, Perez-Padilla R, Camelier A, Rosa F, Nascimento $O$, et al. Prevalence of chronic obstructive pulmonary disease and associated factors: the PLATINO Study in São Paulo, Brazil. Cad Saúde Pública 2005; 21: 1565-1573.

17. Ferris BG. Epidemiology Standardization Project (American Thoracic Society). Am Rev Respir Dis 1978; 118: 1-120.

18. The European Community Respiratory Health Survey II. European Community Respiratory Health Survey II Steering Committee. Eur Respir J 2002; 20: 1071-1079.

19. Anonymous. Lung Health Study Questionnaire. Vancouver: BC Cancer Research Center; 2004

20. Standardization of spirometry, 1994 Update. American Thoracic Society. Am J Respir Crit Care Med 1995; 152: 1107-1136.

21. Perez-Padilla R, Vazquez-Garcia JC, Marquez MN, Jardim JR, Pertuze J, Lisboa C, et al. The long-term stability of portable spirometers used in a multinational study of the prevalence of chronic obstructive pulmonary disease. Respir Care 2006; 51: 1167-1171.

22. Menezes AM, Victora CG, Perez-Padilla R. The Platino project: methodology of a multicenter prevalence survey of chronic obstructive pulmonary disease in major Latin American cities. BMC Med Res Methodol 2004; 4: 15. 